\title{
Research on Systemic Risk of Banking Industry from the Perspective of Internet
}

\author{
Qiyao Ai \\ Beijing Jiaotong University, Beijing 100044, China \\ aiqiyaobj@126.com
}

Keywords: Internet perspective; banking industry; systemic risk; contagion mechanism.

\begin{abstract}
Internet finance, as an innovation of cross-border finance, on the one hand, strengthens the connection between Internet finance and traditional banking industry, on the other hand, intensifies the risks of commercial banks, produces shocks and opens up risk contagion channels. Based on the Internet, this paper combs the relevant literature, summarizes the connotation of risk, explores the triggering factors of systemic risk in banking industry, and analyzes the risk generation mechanism from two aspects of contagion mechanism and common impact, and constructs the risk transmission path from two aspects of real and pure connection channels. A comparative study of systemic risk classification and characteristics changes in banking industry from the perspective of Internet is presented. The results show that Internet factors aggravate the contagion of systemic risk in banking industry.
\end{abstract}

\section{Introduction}

Internet finance, as an innovation in cross-border finance, has a very important impact on China's banking industry. While the Internet brings universality, convenience, richness and transparency to the banking industry, it also has a huge impact on the banking industry. On the one hand, the connection between Internet Finance and traditional banking industry has created innovative cooperation; on the other hand, the Internet has impacted the traditional banking industry and opened up the channel of risk contagion.

Hernando (2007), Atay (2008), Ciciretti (2009) and others believe that online banking has an impact on bank deposits, loan services and bank profits. Initially, the impact was positive, but as time went on, the effect gradually became negative. Onay and Ozsoz (2013) also indicated that the rapid loan approval and lower loan interest services of online finance have impacted the loans of traditional banks.

In China, some scholars have summarized the dynamic logic of systemic risk evolution in banking industry. Fan Xiaoyun (2013) divides the systemic risk into five stages: hidden danger stage, mutation stage, risk contagion stage, adjusting the non-financial part of the behavior stage and crisis outbreak stage.

The above research shows that the dynamic logic of Banking Systemic Risk Evolution from the perspective of the Internet can be divided into the following stages. The first stage is the hidden danger stage, because the various behaviors conceal the risk, the systematic risk gradually accumulates, which becomes the vulnerable factor in the financial field; the second stage is the contagion stage, because of the accumulation of risk, once the outbreak, because of liquidity and business overlap, the speed of risk contagion accelerates; the third stage is the contagion stage. In order to break out in an all-round way, banks and banks, institutions and institutions interact with each other, and systemic crises erupt in an all-round way. 


\section{The systemic risk generation mechanism of banking industry from the perspective of Internet}

\subsection{Influencing factors}

The inducement factors of banking systemic risk from the Internet perspective include external factors, endogenous factors and Internet factors.

\subsubsection{External factors}

(a) Economic cycle factors

The economic cycle is the law of economic operation, and it is also an important factor affecting the systemic risk of banks. During the economic downturn, because of the reduction of bank deposit business, the bank's money stock is reduced, and there is a hidden danger of systemic risk, which makes the banking industry more depressed and more likely to lead to a more serious economic crisis.

(b) Psychological expectation factors

Psychological anticipation is also one of the factors that affect banking risk. If psychological expectations are relatively low, people will give up investment, reduce consumption, and even withdraw deposits, which will lead to the reduction of bank reserves and potential risks. The spread of risk and the transmission of confidence crisis have caused the society to suffer from a crisis of confidence.

(c) Exchange rate and interest rate factors

Exchange rate risk is the risk of converting local currency into foreign currency or foreign currency into cost currency when investing in foreign exchange. The fluctuation of exchange rate is related to the profitability of banks, and the fluctuation of foreign exchange has become a factor of systemic risk of banks.

\subsubsection{Endogenous factors}

(a) Banking business mode

From the perspective of the Internet, the systemic risk of banking industry presents a three-dimensional trend, which may lead to cross-contagion. With the increase of transaction volume, large amount of information exchange, 24-hour network interconnection, the effectiveness of financial physical isolation is weakened, the cross-penetration between banks, banks and individuals is complex, the scope of risk is expanded, and the infectivity is aggravated.

(b) Bank financing structure

Under the influence of high leverage rate, bank financing business may produce systemic risk. Once the high leverage institutions fail, the risk will be transmitted to the institutions providing credit guarantee for a long time, and their liquidity will also be affected, which will aggravate the fluctuation of the market. Market instability and rapid spread of potential risks may lead to the collapse of the whole system.

\subsubsection{Internet factors}

Whether external or endogenous, Internet factors are involved. There are more close links between individual banks and hidden loopholes in the Internet. Both of these will expand the scope of systemic risk impact and aggravate the systemic risk contagion in the banking industry.

\subsection{Generation mechanism}

\subsubsection{Infection mechanism}

For individual banks, systemic risk is not only from their own internal, but also from external risk contagion. That is to say, on the basis of the theory of financial vulnerability, even if a bank develops steadily, if it is contagious by the risk of other banks, it may fall into crisis.

Risk is contagion based on the assets and liabilities channels of the banking system. The interbank 
market will improve the liquidity among banks, but there is also the possibility of risk contagion. From the perspective of the Internet, the contagion of systemic risk in the banking system may lead to bankruptcy and other problems, even the collapse of the entire banking industry. It can be analyzed from the following aspects:

(a) The basis of asset liability relationship. The bond debt relationship between banks can be formed through the following ways. Firstly, there are links between banks in the way of financing funds; secondly, the relationship between creditor's rights and liabilities formed by the payment system. From the perspective of the Internet, there are more and more business between banks, such as transfer, collection and payment, and the relationship between creditor's rights and liabilities is complex.

(b) Channels for contagion of assets and liabilities. From the Internet perspective, banks are more closely linked, and risk shocks may be through business interactions between banks. Sometimes participants fail to perform, which can lead to a series of default reactions by other participants, and the whole banking industry is in trouble.

(c) Payment system. From the perspective of internet, the integration of payment system makes all banks united and forms a network system of creditor's rights and liabilities. Fine payment errors among banks may cause crisis, accelerate risk contagion and expand risk Xiaoying. Once a bank has difficulty paying, the remaining banks will withdraw their deposits to protect their positions, leading to liquidity and credit crises.

\subsubsection{Common impact}

A macro or large-scale impact on the economic system has led to the paralysis of the entire market. This phenomenon is called joint impact. One of the forms of joint impact on banks is psychological expectation and herd behavior model. The operation of a bank depends largely on public confidence. Confidence is like risk. It's contagious. If a group of people lose confidence, it will also reduce the psychological expectations of the surrounding people and form a crisis of confidence. A series of information cascading reactions lead to behavior called herding behavior. When herd behavior occurs, from the perspective of the Internet, it is easy for individuals and individuals to form a trend of consistent action, and shocks will lead to the deviation of behavior. The crisis of confidence has occurred, the phenomenon of deposit runs has occurred, and the banking industry is facing a crisis.

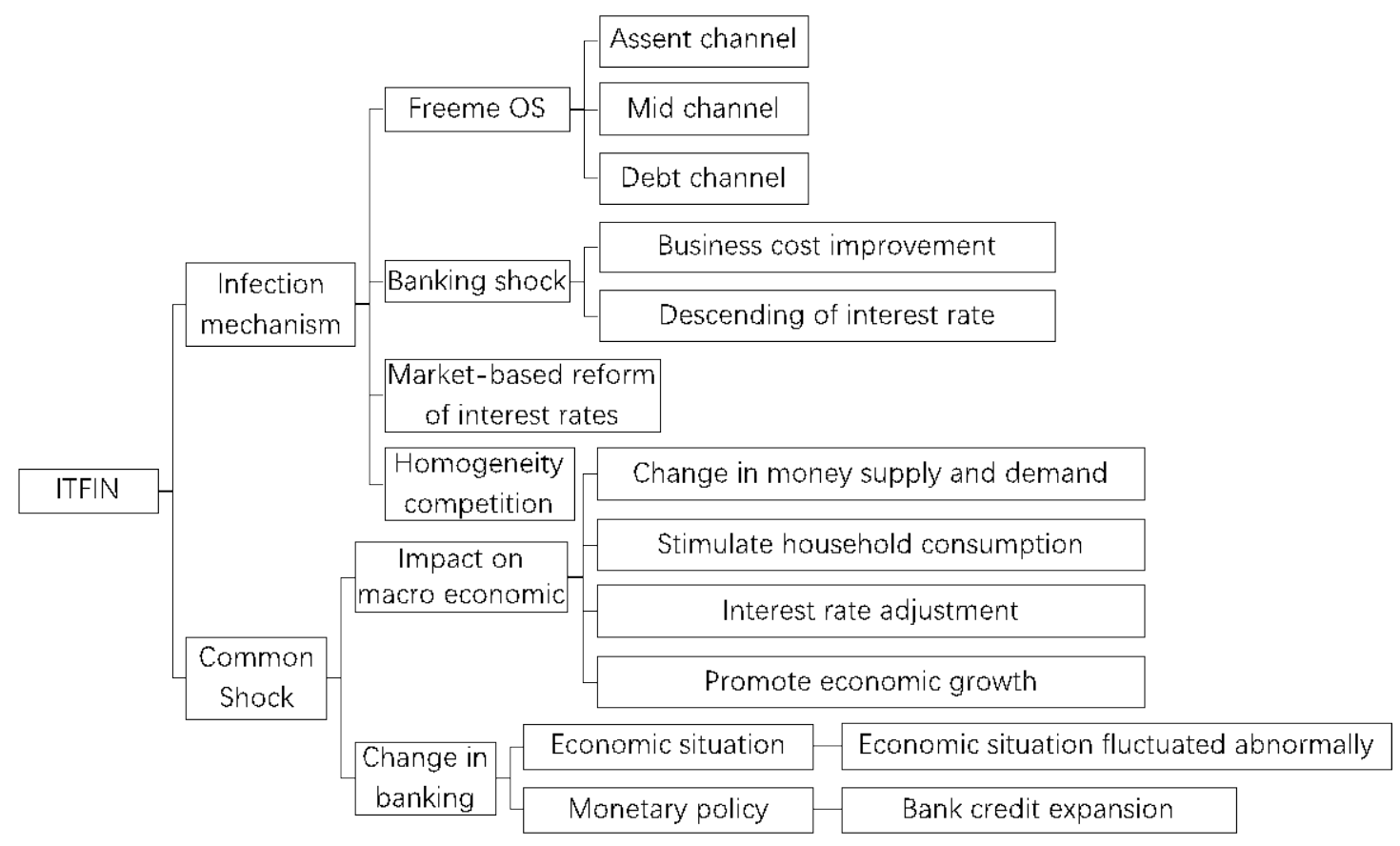

Figure 1. The systemic risk generation mechanism of banking industry from the Internet perspective. 


\section{The systemic risk contagion path of the banking industry from the Internet perspective}

Internet finance and banking constitute a complex and fragile relationship network. Because of the cross of fund trusteeship bridge and financing and credit platform, Internet finance will spread risks to the banking industry, causing systemic risks in the banking industry. From the perspective of Internet, the transmission path of banking systemic risk refers to the path formed when Internet financial risk or banking systemic risk spread risk to other banks through related business.

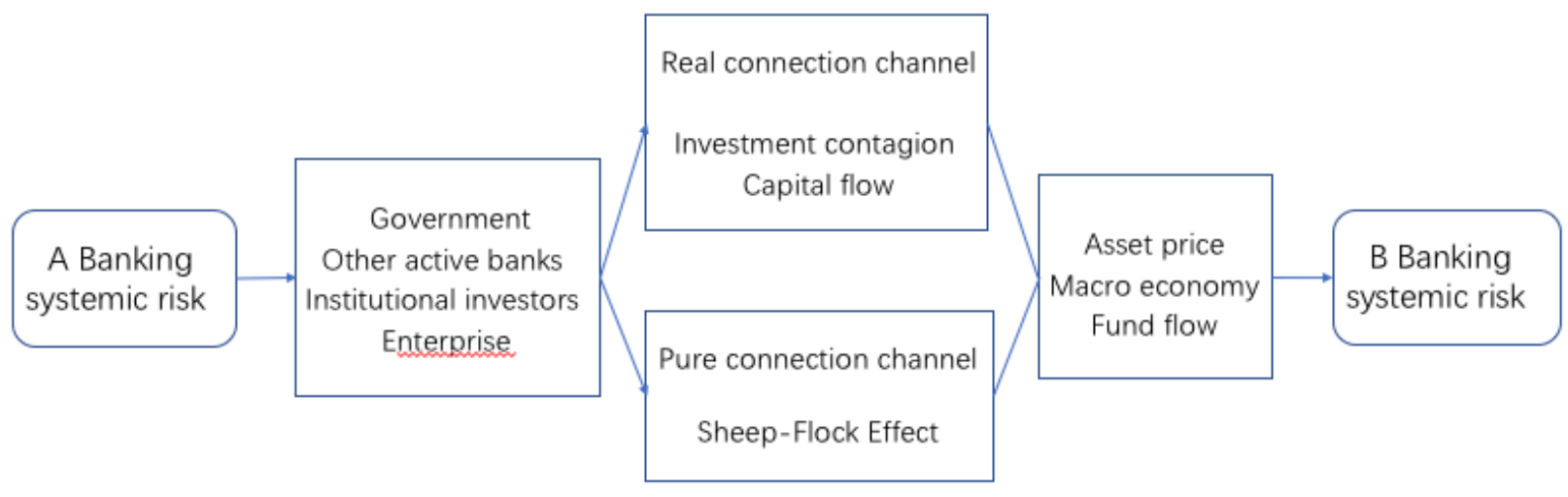

Figure 2 systemic risk contagion path in banking industry from the Internet Perspective

\subsection{Real contact channels}

\subsubsection{Investment channels}

Each bank has carried out a variety of Internet business, and jointly carried out with various financing platforms. The relationship between banks has also been enhanced because of payment business. If a bank's financial products are profitable, it may attract a large number of investors to withdraw funds from other banks for investment, which has a negative effect on other banks. If a bank is in crisis, then bank customers may suffer losses, which can also cause crises in other banks where customers are located.

\subsubsection{Capital flow channel}

The financial spillover effect is generally transmitted through three channels. Here we mainly discuss the financial crisis transmission through the banking system. A bank's crisis can cause bank depositors and portfolios to worry about the health and stability of the entire banking system. It can lead to the phenomenon of withdrawing cash or reducing purchases of financial products, reducing bank loans and finally facing the risk of bankruptcy. Under the influence of herding, the whole banking system is in danger.

\subsection{Pure channels of contact}

The special form of transmission is pure infection. When the transmission is continuous and large, transmission becomes infection. The important condition for its realization is the existence of herding behavior. When contagion occurs, the corresponding transmission mechanism changes. Once a crisis occurs and systemic risk factors are exposed, panic will occur in the whole financial and economic market, and herding effect will show. The psychological crisis of a bank is often transmitted to other banks through pure psychological channels. 


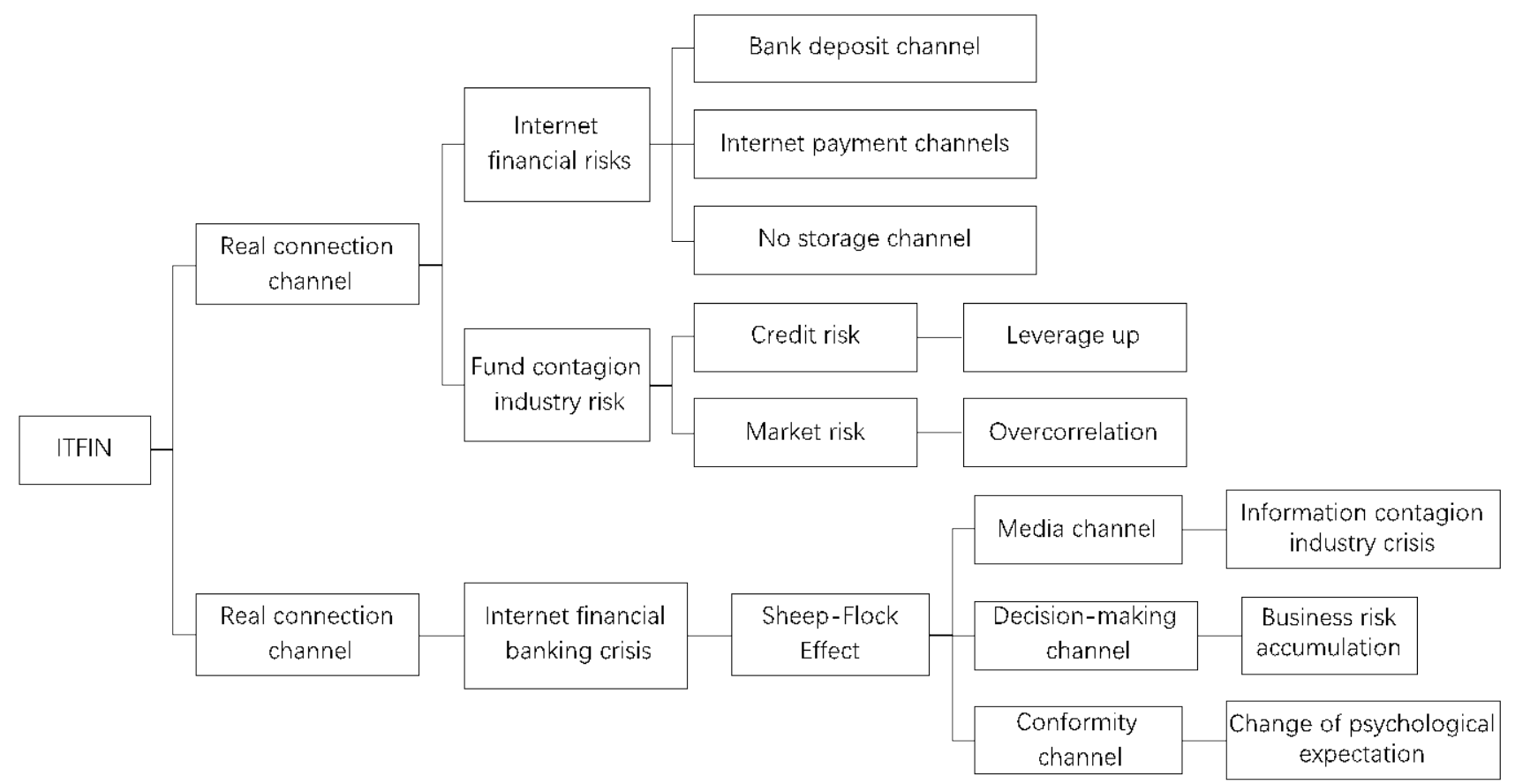

Figure 3 systemic risk contagion mechanism in banking industry from the Internet Perspective

\section{Systemic risk changes in the banking sector from the Internet perspective}

The change of systemic risk in banking industry from the perspective of Internet will be explained from two aspects: risk classification and risk characteristics.

\subsection{Risk classification changes}

From the perspective of the Internet, due to external shocks, both the classification and the meaning of the classification of systemic risk in banking industry have new connotations and extensions on the original basis.

\subsubsection{Credit risk}

Systemic credit risk refers to the risk caused by external uncertainties. In the process of economic operation, unpredictable situations will happen accidentally and randomly, which may impact the system. From the perspective of the Internet, various kinds of P2P platforms have emerged one after another, some of which hide credit risks, the rate of non-performing loans has increased, and the credit crisis has intensified.

\subsubsection{Interest rate and exchange rate risk}

Interest rate risk mainly refers to the potential impairment risk of assets caused by the change of interest rate; exchange rate risk mainly refers to the impairment risk of future cash flow caused by the change of exchange rate. The two are interrelated and interact. From the perspective of the internet, various funds and financial products headed by Baobao have been emerging, and interest rate risk has increased.

\subsubsection{Country risk}

State risk usually refers to the possibility of loss of economic interests caused by a specific factor of a country, such as politics, economy and so on. From the perspective of internet, with the opening of economy and trade, banking business is becoming more and more complex. More and more transactions are completed through the internet. The amount of transactions is huge and frequent. Once the unstable factors in the Internet are exposed, it will impact the banking industry and even lead to the economic crisis of many countries. 


\subsection{Changes in risk characteristics}

In recent years, with the rapid development of banking finance, bond underwriting and investment, the banking system has been continuously strengthened. From the perspective of the Internet, the characteristics of banking system risk have changed.

\subsubsection{Changes in risk characteristics from the Internet Perspective}

(a) Enhanced universality

In the era of continuous development of various economic platforms on the Internet, economic and business contacts are closer and the links between institutions are more complex. Therefore, in the normal business development, we should pay full attention to the universality of systemic risk in banking industry and play the role of risk prevention.

(b) Infectious aggravation

As the Internet continues to penetrate into the banking industry, the risk of infection is significantly enhanced. Under the Internet perspective, the banking environment and related businesses are changing. The increasing correlation between banking and financial institutions has increased the risk of contagion.

(c) Improvement of concealment

From the perspective of the Internet, risks become more hidden. Some enterprises use multi-head financing to conceal risks. At the same time, different degrees of implicit guarantee appear in financial management, consignment and other business operations, which improves the concealment of risks.

(d) Externality amplification

Because of the convenience and informationization of the Internet, the degree of banking business association has been improved, and the degree and scope of risk occurrence have been expanded. The Internet is highly transferable. Once a crisis breaks out, it can cause a chain reaction among banks, which can expand from individuals to the whole market.

(e) The system is more fragile.

Because banks account for a large proportion in the financial system, although the Internet improves business efficiency, it also improves the vulnerability of the financial system, resulting in risks that may endanger national financial security.

\subsubsection{New features of risk from the Internet Perspective}

(a) Self-reinforcement

In the process of risk contagion, the degree of risk continues to increase, that is, risk self enhancement. Information asymmetry in the market and people's rational economic behavior will aggravate the spread of systemic risk. From the perspective of the Internet, the phenomenon of information asymmetry has been alleviated, but the lack of uniformity of data standards makes the phenomenon of information asymmetry still exist.

(b) Informatization

From the perspective of the Internet, increasing leverage through information increases the efficiency of factor resources, and this fluctuation is sharply magnified. After a period of time, the impact is reflected on the time axis. Even a small platform business, under the influence of information leverage, will form a large fluctuation, which will impact the banking system.

\section{Conclusion}

As an innovation of financial mode, the risk contagion of banking industry is aggravated from the perspective of Internet. This paper analyses the inducement factors of systemic risk in banking industry from the perspective of internet, explores the risk generation mechanism from two aspects of contagious tact and common impact, constructs the transmission path of real and pure connection channels, and summarizes the classification and characteristics of risks. The conclusion shows that from the perspective of the Internet, the business environment and business model of banks have been 
affected, the fuse of risk has changed, the Internet has improved the degree of association among banks, and the contagion mechanism is the main cause of systemic risk. At the same time, the externality, contagiousness, concealment, self-enhancement and vulnerability of systemic risk are more prominent in the context of the Internet.

\section{References}

[1] Yener Altunbas, John Goddard, Phil Molyneux. Technical change in banking [J]. Economics Letters, 1999, 64(2).

[2] Ignacio Hernando,María J. Nieto. Is the Internet delivery channel changing banks' performance? The case of Spanish banks [J]. Journal of Banking and Finance, 2006, 31(4).

[3] Atay,E.,2008. Macroeconomic Determinants of Radical Innovations and Internet Banking in Europe, Annales Universitatis Apulensis Series Oeconomica,Vol. 2,No. 10:1-4.

[4] Rocco Ciciretti, Iftekhar Hasan, Cristiano Zazzara. Do Internet Activities Add Value? Evidence from the Traditional Banks[J]. Journal of Financial Services Research, 2009, 35(1).

[5] Zhu Chen, Hua Guihong. The Impact of Internet Finance on Systematic Risk of China's Banking Industry: An Empirical Study Based on SCCA Model and Stepwise Regression Method [J]. Financial Economics Research, 2018, 33 (02): 50-59.

[6] Fan Xiaoyun, Fang Yi, Wang Daoping. Dynamic Characteristics of Systemic Risk of Chinese Banks and Screening of Systematic Important Banks - Analysis Based on the Combination of CA and DAG [J]. Financial Research, 2013, 11:82-95. 